\title{
Reúso de água em indústria de reciclagem de plástico tipo PEAD
}

\author{
Water reuse on HDPE plastics recycling pack industry
}

\author{
Angela Cristina Orsi Bordonalli \\ Doutora em Saneamento e Ambiente pela Faculdade de Engenharia Civil, Arquitetura e Urbanismo da Universidade Estadual de Campinas (Unicamp). \\ Pesquisadora da Unicamp
}

\section{Carlos Gomes da Nave Mendes}

Doutor em Hidrálica e Saneamento pela Escola de Engenharia de São Carlos (EESC) da Universidade de São Paulo (USP). Professor adjunto da Faculdade de Engenharia Civil, Arquitetura e Urbanismo da Unicamp

\begin{abstract}
Resumo
A discussão acerca da viabilidade técnica, econômica e ambiental do reúso da água em processos industriais tem sido uma preocupação constante. Neste trabalho propõe-se uma alternativa simplificada para o tratamento de efluentes com vistas ao seu reúso em uma indústria de reciclagem de plásticos. A água, no presente caso, é componente fundamental para o processo, já que participa como elemento de remoção de detritos e impurezas que contaminam a matriz da matéria-prima utilizada, proveniente, principalmente, de aterros sanitários e lixões. As embalagens plásticas recicladas pela indústria em questão são, em sua grande maioria, de uso doméstico e, em menor escala, frascos contaminados com óleos lubrificantes. Os resultados demonstraram a viabilidade do tratamento através de processo físico-químico por coagulação, floculação, decantação e filtração em manta geotêxtil, com o uso do hidroxicloreto de alumínio (PAC) como coagulante, soda cáustica (50\%) como alcalinizante e polieletrólito como auxiliar de floculação e desidratação do lodo, bem como a exequibilidade do reúso dos efluentes em circuito fechado.
\end{abstract}

Palavras-chave: reúso de água; óleo lubrificante; reciclagem de plásticos tipo PEAD; tratamento físico-químico.

\begin{abstract}
The discussion about technical, economical and environmental feasibility of water reuse in industrial process has been a constant concern. This paper purposes a simplified choice for waste water treatment seeking reuse in a plastic recycle industry. The water, in this case, is a prime component because it is the main element for the debris and impurities removal that contaminates the matrix of plastic raw material, which comes, mostly, from landfill and waste disposals. The recycled plastic packages, from the company that had been used for this research, come mostly from domestic use and, in a minor scale, the plastic package contaminated by lubricant oil. The final results show feasible for the treatment through physical-chemical process by coagulation, flocculation, decantation and filtration on geotextile, with the use of aluminum hidroxichloride (PAC) as coagulant, sodium hydroxide as alkaliner, polyelectrolyte as auxiliary on flocculation and slush dehydration, as well as the workability of the effluents reuse under a closed circuit proved itself the technical, economical and environmental feasibility.
\end{abstract}

Keywords: water reuse; lubricant oil; HDPE plastics recycle; physical-chemical treatment.

\section{Introdução}

Na tentativa de equacionar a diversa gama de problemas ambientais, a ciência tem contribuído para o avanço de tecnologias mais limpas e do desenvolvimento de processos chamados super clean. No entanto, algumas dessas tecnologias, como aquelas que têm sido usadas em reúso de água, podem não ser economicamente viáveis para indústrias de pequeno e médio porte, cuja água para reúso não necessita de pureza. Faz-se necessário, portanto, o desenvolvimento de outras técnicas que atendam a todos os segmentos de mercado.
A questão desses efluentes nos induz a uma reflexão sobre os meios atuais de produção e hábitos de consumo, fazendo-se necessária a adoção de novos valores e a reflexão acerca do modo de vida do ser humano. A dimensão ambiental vem sendo incorporada ao processo produtivo das indústrias e à gestão empresarial, inclusive como base para redução de custos e aumentos de lucratividade, por meio de medidas para minimização, reúso e reciclo dos efluentes líquidos gerados pelos diversos processos industriais (SANTOS; MIGUEL, 2002).

Enfocando-se o caso específico das embalagens plásticas descartadas por usuários urbanos e rurais como embalagens de alimentos, 
produtos de limpeza doméstica e frascos de óleo lubrificante, entre outros, evidencia-se o problema ambiental passível de ser gerado por esses resíduos quando dispostos em aterros sanitários ou quando incinerados e, até mesmo, destinados à reciclagem, submetidos a operações de acondicionamento, transporte, triagem, remoção de rótulos, picagem, lavagens e reprocessamento para fabricação de novas embalagens ou outros produtos plásticos. O uso de água nesses processos e a geração de efluentes de alta carga poluidora ocorrem, em geral, em instalações improvisadas de pequeno a médio porte, muitas delas conduzidas por recicladores informais, sem licenciamento para seu funcionamento e sem qualquer compromisso com a legislação ambiental.

Dessa forma, o presente trabalho visa a apresentar alternativas de baixo custo de implantação e operação para o tratamento e reúso de efluentes líquidos gerados em operações de lavagem de embalagens plásticas de diversas origens, utilizando-se dados obtidos em escala real de uma indústria recicladora de plásticos instalada no município de Indaiatuba, São Paulo.

\section{Material e métodos}

\section{Características do processo industrial}

A indústria objeto de estudo deste trabalho foi criada, originalmente, com o intuito de fabricar embalagens de plástico para envase de produtos químicos (detergentes, amaciantes, água sanitária, desinfetantes, etc.) fabricados em outra indústria do mesmo grupo, localizada no mesmo município. Atualmente, cerca de 90\% da matériaprima é constituída por frascos plásticos pós-consumo, alcançando o

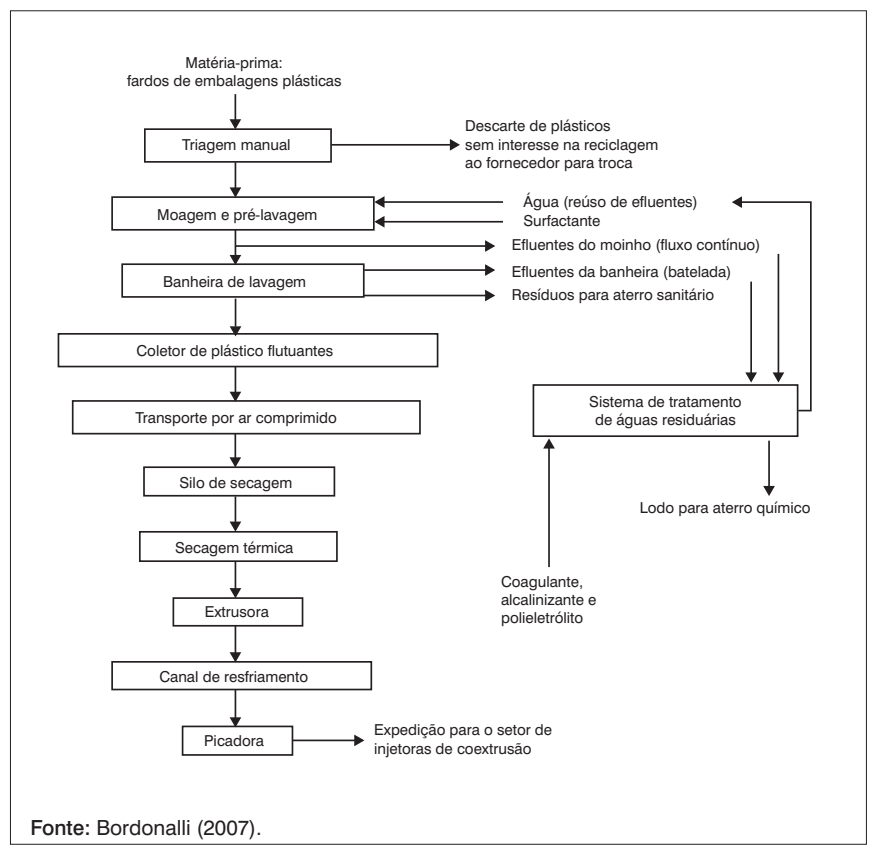

Figura 1 - Fluxograma do processo de reciclagem de plásticos montante de 100 a 200 toneladas/mês, adquirida de três fontes: (1) vasilhames danificados nos processos de fabricação ou envase; (2) material adquirido de cooperativas de coleta seletiva da cidade de Indaiatuba e, (3) material adquirido de aterros sanitários/lixões das cidades vizinhas.

As diferentes origens da matéria-prima geram dois tipos de lotes com características distintas em termos de contaminação, cujos reflexos são estendidos aos efluentes gerados. Nos lotes de vasilhames que retornavam do processo de envase, a matéria-prima encontra-se praticamente limpa de contaminação externa, enquanto a oriunda da coleta seletiva e aterros/lixões manifesta teores variados de contaminantes, dependendo do contato com outros resíduos urbanos e industriais, além da influência de sua origem, triagem, armazenamento, exposição a chuvas e solos e transporte até a indústria. O fluxograma dos processos empregados pela indústria está representado na Figura 1.

\section{Estudos laboratoriais preliminares}

Um grande problema na reciclagem de resíduos plásticos é o tratamento do efluente de lavagem, o qual contém uma alta carga poluidora e, justamente por causa de seus elevados níveis de contaminação orgânica e inorgânica, não pode ser descartado sem tratamento (BORDONALLI; MENDES, 2005).

Para Mierzwa (2002), no reúso de efluentes tratados, uma das principais preocupações é o processo de concentração de contaminantes específicos, que reduz o potencial de reúso e pode comprometer as atividades que empregarão essa água.

A definição do processo a ser implantado na empresa, objetivando o tratamento de efluentes e visando ao reúso da água, teve como etapa preliminar a realização de estudos de tratabilidade desenvolvidos no Laboratório de Estudos de Tratabilidade de Águas e Resíduos (LabPró), vinculado ao Departamento de Saneamento e Ambiente (DSA) da Faculdade de Engenharia Civil, Arquitetura e Urbanismo (FEC) da Unicamp.

Com base em estudos prévios realizados em 2004 (BORDONALLI; MENDES, 2005), descartou-se a alternativa de tratamento por processo biológico (lodos ativados por batelada), cujos resultados demonstraram eficiência muito aquém das obtidas por processo físico-químico (pré-filtração, coagulação, floculação, decantação e filtração), ambos simulados em equipamentos de bancada, tipo jarteste. Destacam-se, a seguir, as principais conclusões dessa fase do trabalho.

- Os estudos de tratamento físico-químico desse tipo de efluente indicaram como melhor coagulante o Hidroxicloreto de Alumínio (PAC) em comparação ao cloreto férrico e sulfato de alumínio.

- As condições necessárias para a floculação foram: (i) gradiente de velocidade igual a $60 \mathrm{~s}^{-1}$; (ii) período de floculação dez minutos.

- A clarificação do efluente por simples sedimentação demonstrouse insuficiente, sendo necessária uma etapa complementar de 
filtração, no caso, com o uso de mantas geotêxteis sintéticas nãotecidas.

- As eficiências de remoção de DQO, turbidez e fosfatos, corresponderam a valores de 93,2\%, 99\% e 98,6\%, respectivamente, resultados que favoreceram a hipótese da possibilidade de reúso dos efluentes tratados no próprio processo de lavagem de embalagens plásticas.

- O volume de lodo adensado gerado na decantação resultou em valores variáveis entre 50 e $53 \mathrm{~mL} / \mathrm{L}$ para as condições estabelecidas nos ensaios realizados: uso de Cone Imhoff, com um período de sedimentação de 30 minutos

\section{Descrição do sistema de tratamento de águas residuárias implantado}

As principais características da instalação quanto a vazões são aqui relacionadas:

- quantidade de plásticos reciclados/hora $=600 \mathrm{~kg}$;

- turno único (atualmente) = oito horas/dia (4.800 kg plásticos/dia);

- volume de água por kg de plástico reciclado = 2 a $3 \mathrm{~L}$;

- quantidade de água consumida no processo = 10 a 15 m³/dia;

- vazão média horária durante o período de funcionamento da indústria $=1,5 \mathrm{~m}^{3} /$ hora;

- vazão nominal do sistema de tratamento $=2,0 \mathrm{~m}^{3} / \mathrm{hora}$.

Para Giordano (1999), os processos de tratamento a serem adotados, as suas formas construtivas e os materiais a serem empregados são considerados a partir dos seguintes fatores: a legislação ambiental regional; o clima; a cultura local; os custos de investimento; os custos operacionais; a quantidade e a qualidade do lodo gerado na estação de tratamento de efluentes industriais; a qualidade do efluente tratado; a segurança operacional relativa aos vazamentos de produtos químicos utilizados ou dos efluentes; explosões; geração de odor; interação com a vizinhança; confiabilidade para atendimento à legislação ambiental; possibilidade de reúso dos efluentes tratados.

Para Westerhoff e Chowdhury (1996), o tipo de fonte de abastecimento de água, superficial ou subterrânea, provoca variações no arranjo do sistema de tratamento, já que as características da água bruta influenciam na escolha das técnicas de tratamento. Neste caso, em se tratando de efluentes, a mesma afirmação é válida. Para Mierzwa e Hespanhol (2005), em termos práticos, o que realmente interessa no processo de coagulação, floculação e clarificação é a dosagem e a condição ótima para a aplicação do coagulante, etapa de grande importância no tratamento, uma vez que as etapas subsequentes dependem dela.

Os autores explicam que isso ocorre porque as reações químicas envolvidas são muito rápidas e dependem da energia da agitação, da dose do coagulante, do pH e da alcalinidade da água. Caso essas condições estejam corretas, existirão condições plenas para o sucesso da instalação, evidentemente, quando as etapas complementares forem projetadas e operadas de forma adequada.

As etapas do processo de tratamento implantado no sistema de tratamento de águas residuárias (STAR) podem ser visualizadas no fluxograma apresentado na Figura 2.

Com o início de operação do STAR, algumas alterações foram necessárias, destacando-se:

(i) inclusão de sistema de preparação e dosagem de polieletrólito catiônico como auxiliar de floculação e de desaguamento dos lodos gerados;

(ii) substituição dos leitos de secagem por big bags suspensos em função de diversos problemas de ordem operacional provocados pela excessiva presença de sólidos grosseiros e lodos gerados no tratamento desse tipo de efluente, dificultando as etapas de desaguamento e desidratação de sólidos e lodos, principalmente sob os aspectos da necessidade de limpezas frequentes, troca de materiais filtrantes e alto teor de umidade nos resíduos gerados;

Dessa forma, por iniciativa da própria equipe operacional, foram feitos testes de armazenamento do excesso de lodo em big bags, previamente suspensos em estrutura metálica de sustentação, normalmente utilizada para essa finalidade no processo produtivo, facilitando os procedimentos de transporte por empilhadeiras. A disponibilidade desse equipamento, no presente caso, foi decorrente de seu uso para acondicionamento e transporte dos plásticos lavados e pellets reciclados. Tais testes demonstraram grande vantagem dos big bags em relação aos leitos de secagem tanto sob o aspecto de secagem dos sólidos e lodos gerados no STAR, como pela facilidade de operação, transporte e armazenamento dos resíduos sólidos gerados. Dessa forma, optou-se pelo abandono dos leitos de secagem e estruturação

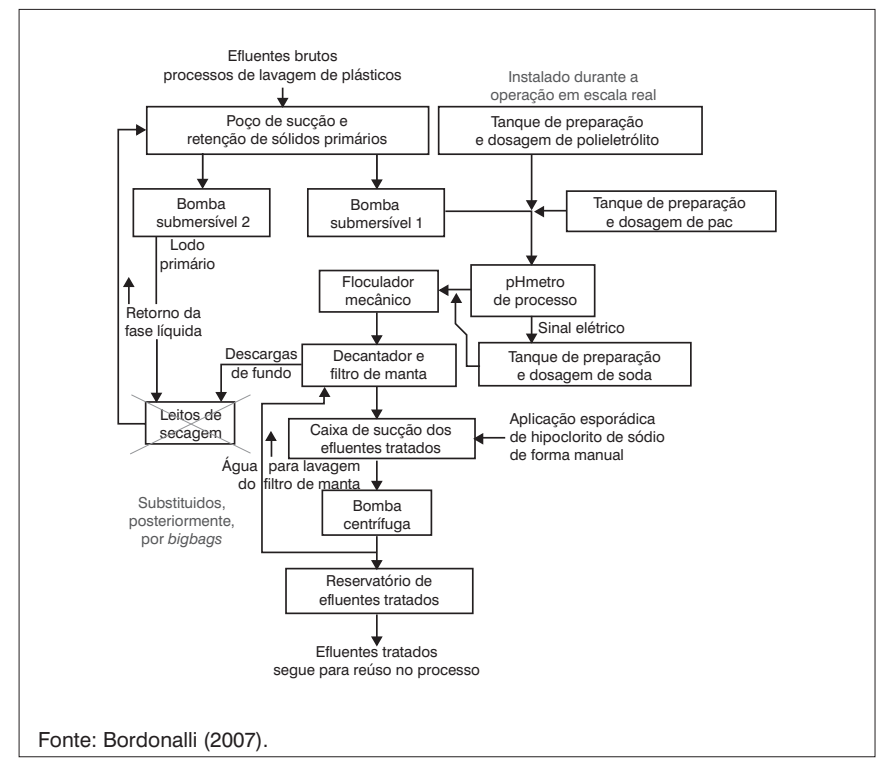

Figura 2 - Fluxograma do processo de tratamento de efluentes visando ao seu reúso 
de diversos big bags sobre cada um deles, utilizando-se as já existentes tubulações do fundo dos leitos para a condução da água drenada até o poço de sucção.

A Figura 3 apresenta uma visão geral do STAR, de um big bag em uso e de amostras dos efluentes em diversas fases do tratamento.

\section{Resultados e discussão}

\section{Dados do processo de reciclagem de plásticos}

Com o objetivo de minimizar o consumo de água, a empresa implantou o reúso total dos efluentes tratados no STAR nas operações de pré-lavagem (moinho) e lavagem (banheira) dos plásticos em processo de reciclagem. Além desses dois pontos de geração de efluentes, somam-se as águas cinzas, provenientes de instalações sanitárias do tipo bebedouro, tanque e lavatório, e, para complementar as perdas inerentes ao processo (evaporação, respingos e arraste com resíduos e plásticos lavados e lodo químico), são incorporados de forma parcial às águas pluviais precipitadas sobre as áreas impermeabilizadas do STAR e da cobertura do galpão de reciclagem.

A maior parte da matéria-prima adquirida é transformada em pellets usados na fabricação de novas embalagens. Porém, uma parcela é destinada a troca por novos lotes, já que interessam apenas os plásticos tipo PEAD, PEBD e PEBDL. O restante, gerado nas operações de triagem e descargas de fundo da banheira, é descartado como resíduo sendo, então, encaminhado para aterro sanitário.

\section{Dados do processo de tratamento e reúso de efluentes}

Os dados apresentados neste item referem-se às características qualitativas dos efluentes brutos e tratados coletados no STAR entre outubro de 2006 e janeiro de 2007. As amostras de efluente bruto foram coletadas em derivação da tubulação de recalque ao floculador, em ponto a montante da introdução dos produtos químicos utilizados no tratamento. Dessa forma, representam-se as características qualitativas do que foi efetivamente tratado no STAR. É importante salientar que uma parcela dos sólidos grosseiros já havia sido removida na câmara inicial do poço de sucção, cujo direcionamento é feito diretamente aos big bags para desaguamento.

As amostras de efluentes tratados foram coletadas nos mesmos períodos das amostras brutas, junto à caixa de sucção que permite o bombeamento dos efluentes para reúso nas lavagens de plásticos. Todas as coletas foram feitas em amostras compostas de alíquotas tomadas a cada meia hora durante uma manhã ou tarde de funcionamento do moinho.

A renovação da água presente no circuito foi programada para o início de novembro; antes, porém, foi feita uma coleta das amostras até então circulantes no sistema (coletada em 26 de outubro de 2006). Essa estratégia permitiu o acompanhamento da evolução dos parâmetros de qualidade durante um ciclo de três meses (novembro a janeiro) sem renovação da água, a não ser pela admissão de parcela das águas pluviais precipitadas na indústria, repondo o volume perdido por evaporação, respingos e arraste com os plásticos lavados e lodos gerados no tratamento, conforme mencionado anteriormente.

Na Tabela 1 são apresentados as eficiências médias e os valores obtidos para todos os parâmetros de qualidade monitorados durante o período de outubro de 2006 a janeiro de 2007.

Como já era previsto, a partir da renovação da água diariamente, houve acréscimo na concentração de sais dissolvidos tanto nos efluentes brutos, como nos tratados. A agregação de sais é proveniente do material removido dos plásticos durante suas lavagens e, principalmente, da adição dos produtos químicos inerentes ao tratamento, destacando-se o coagulante (sal de alumínio) e a soda cáustica (sal de sódio), além do hipoclorito de sódio, como desinfectante (sódio e cloretos). Esclarece-se que tais sais referem-se a sólidos fixos, ou seja, de natureza inorgânica, cuja presença máxima na água depende de sua solubilidade, no caso, alta.

Dessa forma, espera-se que, em um sistema de circuito hídrico fechado, sem inclusão de etapa de tratamento de desmineralização
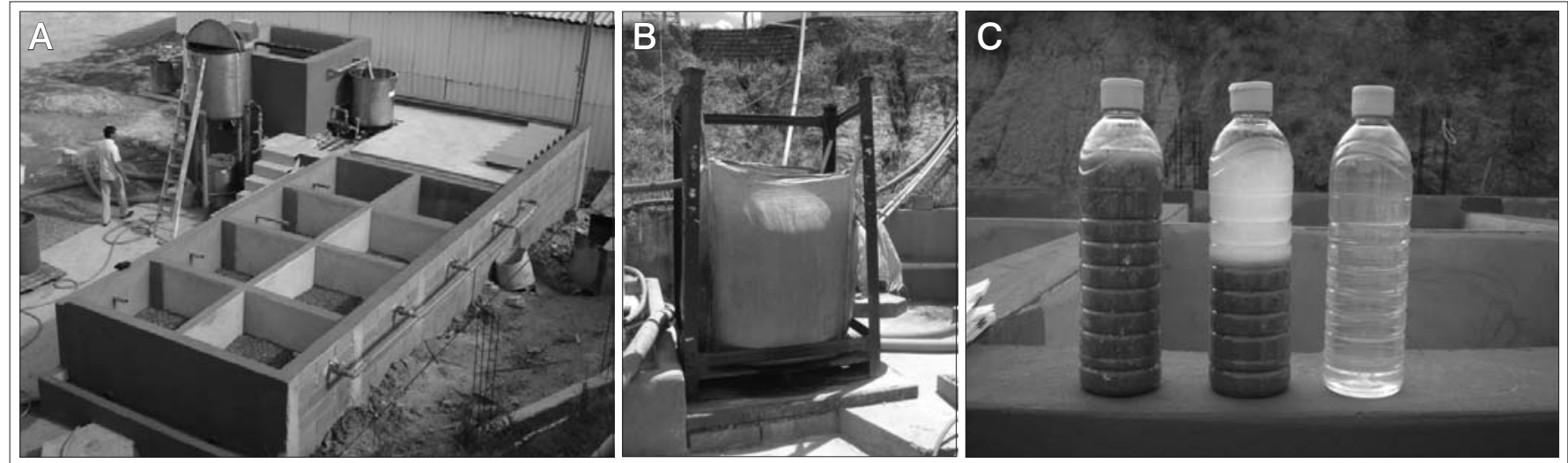

Figura 3 - STAR em construção (A), big bag em uso (B) e amostras dos efluentes bruto, floculado/decantado (um minuto) e filtrado (C) 
Tabela 1 - Parâmetros de avaliação do desempenho do star

\begin{tabular}{|c|c|c|c|c|c|c|c|c|c|}
\hline \multirow[b]{2}{*}{ Parâmetro } & \multicolumn{2}{|c|}{ Média } & \multicolumn{2}{|c|}{ Desvio padrão } & \multicolumn{2}{|c|}{ Mínimo } & \multicolumn{2}{|c|}{ Máximo } & \multirow{2}{*}{$\begin{array}{c}\text { Eficiência } \\
(\%)\end{array}$} \\
\hline & $\begin{array}{c}\text { Efluente } \\
\text { bruto }\end{array}$ & $\begin{array}{l}\text { Efluente } \\
\text { tratado }\end{array}$ & $\begin{array}{c}\text { Efluente } \\
\text { bruto }\end{array}$ & $\begin{array}{l}\text { Efluente } \\
\text { tratado }\end{array}$ & $\begin{array}{c}\text { Efluente } \\
\text { bruto }\end{array}$ & $\begin{array}{c}\text { Efluente } \\
\text { tratado }\end{array}$ & $\begin{array}{c}\text { Efluente } \\
\text { bruto }\end{array}$ & $\begin{array}{c}\text { Efluente } \\
\text { tratado }\end{array}$ & \\
\hline $\mathrm{pH}$ & 7,1 & 8,0 & 0,6 & 0,8 & 6,0 & 7,2 & 7,9 & 9,2 & - \\
\hline Turbidez (UT) & 750 & 19 & 533 & 7 & 125 & 7 & 2.016 & 31 & 97 \\
\hline Condutividade ( $\mu$ S.cm) & 10.601 & 12.534 & 5.521 & 3.893 & 817 & 5.380 & 17.190 & 18.770 & negativa \\
\hline DBO (mg/L) & 2.094 & 777 & 671 & 583 & 1.213 & 143 & 3.543 & 1.851 & 63 \\
\hline DQO (mg/L) & 4.757 & 1.633 & 1.542 & 1.131 & 2.600 & 267 & 7.330 & 3.150 & 66 \\
\hline Óleos e graxas (mg/L) & 76 & 4 & 67 & 3 & 6 & 1 & 227 & 12 & 94 \\
\hline ST (mg/L) & 11.476 & 7.600 & 7.505 & 2.513 & 4.604 & 4.240 & 31.712 & 12.151 & 34 \\
\hline SST (mg/L) & 4.734 & 1.366 & 5.726 & 604 & 1.927 & 610 & 21.500 & 2.370 & 71 \\
\hline SSF (mg/L) & 3.279 & 873 & 5.796 & 381 & 915 & 456 & 20.700 & 1.638 & 73 \\
\hline SSV (mg/L) & 1.455 & 493 & 1.339 & 428 & 393 & 39 & 4.934 & 1.461 & 66 \\
\hline $\mathrm{SDT}$ (mg/L) & 6.741 & 6.234 & 4.032 & 2.967 & 1.104 & 2.936 & 1.1980 & 1.1464 & 8 \\
\hline SDF (mg/L) & 4.843 & 5.284 & 3.456 & 2.777 & 480 & 2.380 & 9.592 & 10.612 & negativa \\
\hline SDV (mg/L) & 1.898 & 949 & 721 & 432 & 616 & 319 & 2.761 & 1.634 & 50 \\
\hline STF (mg/L) & 8.123 & 6.158 & 7.413 & 2.532 & 1.498 & 3.456 & 28.364 & 11.068 & 24 \\
\hline STV (mg/L) & 3.353 & 1.442 & 1.116 & 591 & 1.600 & 784 & 5.712 & 2.582 & 57 \\
\hline Surfactantes (mg/L) & 40 & 16 & 23 & 12 & 11 & 4 & 84 & 44 & 59 \\
\hline
\end{tabular}

(troca iônica ou osmose reversa), suas concentrações serão naturalmente crescentes até seu limite de solubilidade. Já no caso de sólidos de natureza orgânica, tanto suspensos (SSV) quanto dissolvidos (SDV), há moléculas de maior dimensão, várias delas passíveis de remoção pela coagulação com um sal inorgânico como o PAC utilizado no caso, aliado à presença do polieletrólito. Assim, justificam-se as remoções observadas nos parâmetros relacionados à presença de tais substâncias, tais como DBO, DQO, óleos e graxas, surfactantes, SSV e SDV, sem a manifestação de aumento de suas concentrações com o contínuo reúso dos efluentes tratados.

Sob o aspecto da clarificação dos efluentes, verifica-se que houve excelente desempenho do sistema de tratamento implantado, confirmado pelo parâmetro turbidez. As amostras de efluente tratado demonstraram, sistematicamente, aspectos límpidos, conferindo segurança e confiabilidade ao reúso local da água. Com absoluta convicção, pode-se afirmar que, para a finalidade de seu uso na indústria, seu padrão de qualidade não precisa ser elevado. O sucesso nas etapas de clarificação (decantação + filtração) decorreu da correta utilização de produtos químicos para controle do $\mathrm{pH}$ e dos processos de coagulação e floculação, obtida com o uso de dosagens variando entre 4,8 a $6,2 \mathrm{~kg} / \mathrm{m}^{3} ; 2,0$ a $4,4 \mathrm{~kg} / \mathrm{m}^{3}$; e 6,0 a $7,3 \mathrm{~g} / \mathrm{m}^{3}$; respectivamente de hidróxido de sódio; hidroxicloreto de alumínio (PAC) e polieletrólito catiônico.

O uso dos big bags executados em ráfia, com capacidade de uma tonelada, para desaguamento do lodo manifestou resultados satisfatórios quanto aos aspectos econômicos, operacionais e logísticos já que:

- são de baixo custo, aproximadamente R $\$ 10,00$ por unidade (no caso, adquiridos de segunda mão, justificando assim o baixo custo);

- são apropriados para o lançamento do lodo tal qual é descartado de suas fontes geradoras, constituindo-se, após o desaguamento, nos recipientes de armazenamento e transporte até o local de destino apropriado (aterro industrial). Essa vantagem pode ser considerada excepcional, já que a maior dificuldade no uso de soluções de desaguamento sem o emprego de equipamentos (centrífugas, filtros-prensa, mesas desaguadoras etc.) consiste nas operações de remoção e translado do lodo desidratado das unidades de processo e acondicionamento do mesmo;

- são de fácil transporte por empilhadeiras;

- manifestam grande capacidade de drenagem dos líquidos percolados sem, contudo, permitir o transpasse de sólidos em excesso, observação que pode ser comprovada com o retorno da fase líquida ao poço de sucção;

- permitem o acondicionamento de grande volume de material, cerca de $900 \mathrm{~L}$.

A análise do comportamento dos big bags como unidades de desaguamento não pode ser feita com detalhes em função do seu reduzido tempo de operação e, principalmente por serem utilizados duas vezes ao dia na recepção de novas descargas de lodo, seja do decantador ou da câmara de retenção de sólidos grosseiros. Dessa forma, não houve oportunidade de executar coletas de amostras do lodo em processo de desaguamento por diversos períodos, acompanhando a redução do teor de umidade em função do tempo. Os resultados obtidos sobre esse aspecto referem-se às concentrações de sólidos das amostras de lodo e de outras duas, uma para dois dias de desaguamento e outra nas condições finais de estocagem, aguardando transporte para o aterro químico. Esses dados resultaram de amostras compostas coletadas durante as descargas para os big bags; dos próprios, retiraram-se, após homogeneização, volumes de $200 \mathrm{~mL}$, pesados antes e depois da secagem em estufa até a obtenção de peso constante. Os resultados são apresentados na Tabela 2. 
Tabela 2 - Valores das concentrações de sólidos (porcentagem em massa) em amostras de lodo e após 2 e 30 dias de desaguamento

\begin{tabular}{|ccccc|} 
Coleta & $\begin{array}{c}\text { Lodo } \\
\text { primário }\end{array}$ & $\begin{array}{c}\text { Lodo } \\
\text { químico }\end{array}$ & 2 dias & 30 dias \\
\hline 1 & 8,3 & 2,7 & 12,4 & 29,1 \\
2 & 5,8 & 1,8 & 9,5 & 32,5 \\
3 & 9,5 & 2,5 & 13,6 & 25,7 \\
4 & 8,0 & 3,1 & 11,1 & 28,9 \\
\hline
\end{tabular}

Fonte: Bordonalli (2005)

\section{Dados sobre custos operacionais e investimento no STAR}

As Tabelas 3, 4 e 5 apresentam os custos comparativos do processo global (reciclagem + tratamento de efluentes), considerando-se três cenários:

I. tratamento de efluentes na própria indústria e seu reúso;

II. tratamento de efluentes na própria indústria e descarte na rede pública;

III. tratamento de efluentes executado por terceiros.

$\mathrm{Na}$ análise comparativa de custos, considerou-se que no cenário empregado atualmente pela empresa (I), haverá (assim como ocorreu durante o período de levantamento dos dados) a necessidade de descarte do volume total de água presente no circuito hídrico, enviado a tratamento por terceiros uma vez por semestre, com a consequente necessidade de renovação da água no sistema.

Como pode ser observado, a incidência de maior peso no custo do processo de reciclagem recaiu sobre a energia elétrica consumida em todos os equipamentos e, muito próximo a esse, os custos da matéria-prima, ambos com cerca de 32\% em qualquer dos cenários. De forma decrescente, seguem-se a mão-de-obra, transporte, produtos químicos, destinação adequada de lodo e resíduos e, por fim, o custo para reposição de água e destinação adequada dos efluentes residuais, para o cenário $\mathrm{I}$.

Destaca-se que, negligenciando-se a possibilidade de fechamento do circuito hídrico e do tratamento de efluentes pela própria empresa que o gera, o peso do custeio do insumo 'água de processo' passa a ter um peso considerável, passando de 0,27 para 1,01\% e, finalmente, para 5,41\%, respectivamente, para os cenários I, II e III. Tal fato evidencia a importância econômica da implantação de sistemas de tratamento de efluentes industriais, principalmente se estiverem aptos ao fechamento total, ou mesmo parcial, do circuito hídrico implantado por ações de reúso dos efluentes tratados.

Os custos de construção do STAR, para o caso em questão, foram influenciados pelo aproveitamento de diversas unidades já existentes na empresa, tais como reservatórios, tanques de aço inoxidável, turbina do floculador, entre outros, cujos valores foram estimados a custos de mercado como se fossem novos. Além disso, as obras foram desenvolvidas pela própria equipe de manutenção da indústria. Os investimentos são resumidos a seguir:

a) equipamentos:

- bombas dosadoras e tanques de preparação de produtos químicos:

- hidroxicloreto de alumínio: R\$2.150,00

- soda cáustica: $\mathrm{R} \$ 3.850,00$

- polieletrólito: R\$3.850,00

- bombas centrífugas:

- câmara de retenção de sólidos grosseiros: R \$ 1.760,00

- recalque dos efluentes brutos: R\$1.760,00

- recalque dos efluentes tratados: $\mathrm{R} \$ 1250,00$

- pHmetro de processo: $\mathrm{R} \$ 2.865,00$

- rotâmetros: R \$ 830,00

- floculador, incluindo tanque e turbina: $\mathrm{R} \$ 8.500,00$

- caixa de sucção de efluentes tratados: R\$ 1.950,00

- reservatório de água para reúso: $\mathrm{R} \$ 2.120,00$

a) obras civis, incluindo limpeza e preparação do terreno, fundações, estrutura, revestimentos, impermeabilizações e materiais diversos (tintas, brita, areia, cimento, ferragens, escadas, grelhas etc): $\mathrm{R} \$ 38.670,00$

b) instalações hidráulicas e elétricas, incluindo mão-de-obra: $\mathrm{R} \$ 5.340,00$

Total: R\$74.895,00

\section{Conclusões}

O estudo de concepção, implantação e operação em escala real de sistema simplificado de tratamento físico-químico para águas residuárias de indústria de reciclagem de plástico tipo PEAD, incluindo embalagens de óleo lubrificante nos levaram às seguintes conclusões:

A partir do levantamento de custos de implantação e operação do STAR em relação à quantidade de plásticos reciclados e à água utilizada no processo, concluiu-se que o capital de $\mathrm{R} \$ 74.895,00$ investido na construção do STAR pode ser recuperado num período aproximado de 14 meses de operação.

Quanto à influência do reúso de efluentes tratados foi possível estabelecer que:

- o consumo específico da água no processo produtivo não sofreu alteração com a implantação do reúso de efluentes tratados mantendo-se em 2,7 L/kg de matéria-prima reciclada;

- ainda com relação ao consumo de água, nesse tipo de atividade é possível promover o reúso de esgotos cinzas, além da água proveniente de precipitações pluviométricas, as quais, permitem compensar as perdas de água inerentes ao processo produtivo e tratamento de efluentes, que chegaram a 8,3\% do volume circulante diário;

- o reúso da água após o tratamento no STAR proposto confere à água circulante valores crescentes de sais dissolvidos, também 
Tabela 3 - Dados sobre o levantamento de custos do processo global (reciclagem de plásticos + tratamento de efluentes), Cenário I: tratamento de efluentes na própria indústria e reúso da água com renovação a cada semestre

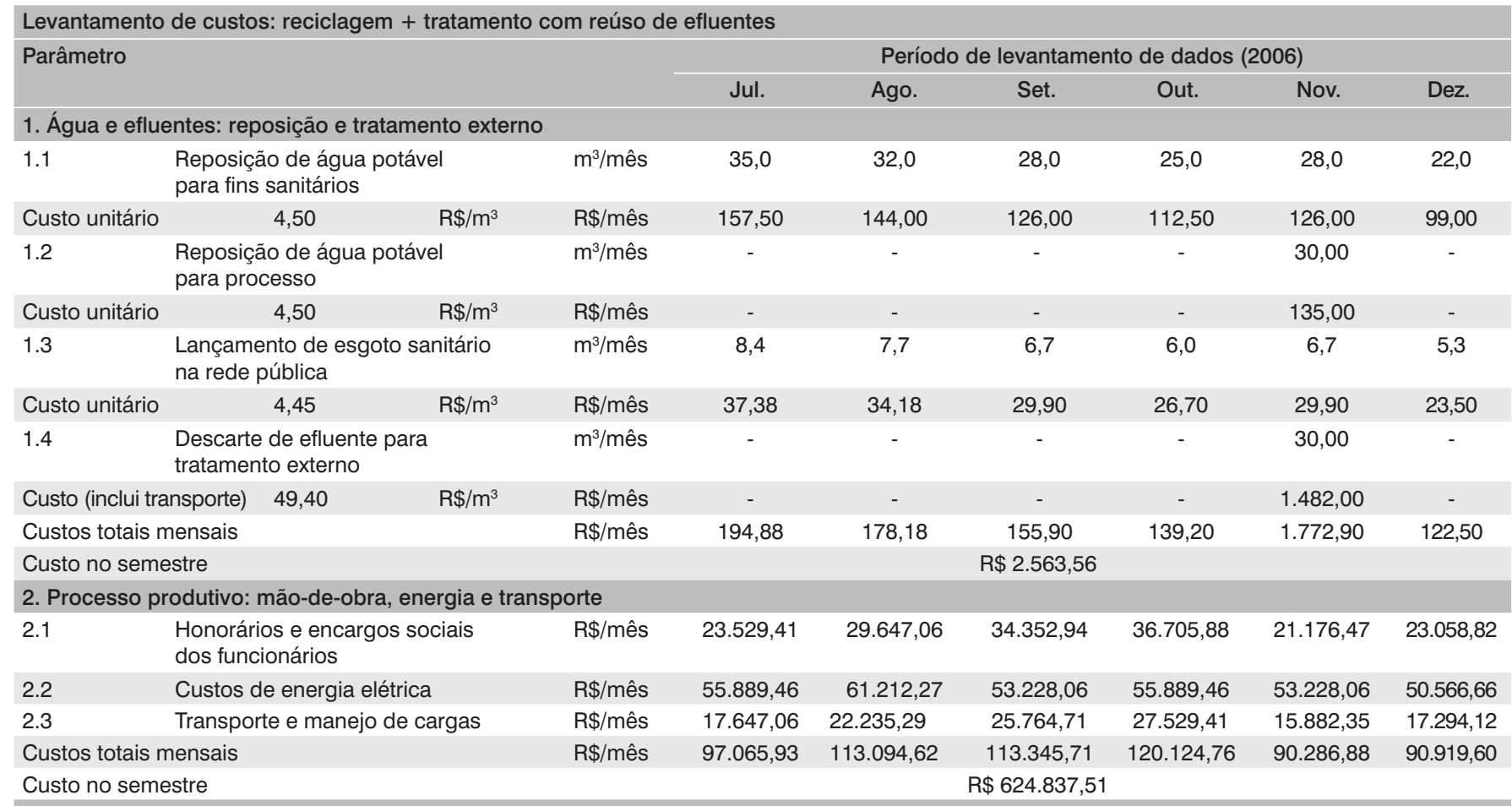

\section{Matéria-prima (inclui impostos)}

\subsection{Compra mensal}

Custo médio unitário $\quad 0,80$

$3.2 \quad$ Processada

3.3 Produção de pellets

Receita média unitária $\quad 4,50 \quad \mathrm{R} \$ / \mathrm{k}$

3.4 Disponibilizada para troca

Receita média unitária $\quad 0,80 \quad \mathrm{R} \$ / \mathrm{kg}$

3.5 Sobras com destino ao fornecedor

Custos totais mensais

Custo no semestre

\section{Produtos químicos: processo e tratamento}

4.1 Compra de tensoativo

Custo médio unitário $\quad 4,45 \quad \mathrm{R} \$ / \mathrm{kg}$

4.2 Compra de hidróxido de sódio (50\%)

Custo médio unitário $\quad 0,98 \quad \mathrm{R} \$ / \mathrm{kg}$ Compra de hidroxicloreto de alumínio

Custo médio unitário $\quad 1,65 \quad \mathrm{R} \$ / \mathrm{kg}$

$4.4 \quad$ Compra de polieletrólito

Custo médio unitário $\quad 25,00 \quad R \$ / k g$

$4.5 \quad$ Compra de hipoclorito de sódio

Custo médio unitário $\quad 1,75 \quad \mathrm{R} \$ / \mathrm{L}$

Custos totais mensais

Custo no semestre

5. Lodo e resíduos (inclui transporte)

\section{1 \\ Resíduos da banheira para aterro} sanitário (seco)

$5.2 \quad$ Lodo desidratado para aterro industrial ton/mês

$\begin{array}{llll}\text { Custo médio unitário } & 222,67 & \mathrm{R} \$ / \text { ton } & \mathrm{R} \$ / \mathrm{mês}\end{array}$

Custos totais mensais $\quad R \$ / m e ̂ s$

Custo no semestre $\quad \mathrm{R} \$$

Custos totais mensais

$\mathrm{R} \$$

L/mês

\section{5}

40

65

146

28

72

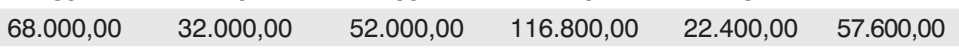

$\begin{array}{llllccc}\text { ton/mês } & 59 & 74 & 86 & 92 & 53 & 58\end{array}$

$\begin{array}{lllllll}\text { ton/mês } & 50 & 63 & 73 & 78 & 45 & 49\end{array}$

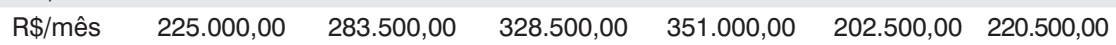
$\begin{array}{lllllll}\text { ton/mês } & 7 & 9 & 10 & 10 & 7 & 7\end{array}$ $\begin{array}{lllllll}\mathrm{R} \$ \text { /mês } & 5.600,00 & 7.200,00 & 8.000,00 & 8.000,00 & 5.600,00 & 5.600,00\end{array}$

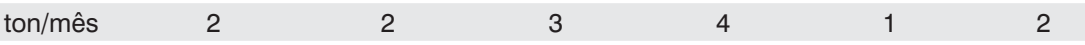
$\mathrm{R} \$$ /mês $\quad 62.400,00 \quad 24.800,00 \quad 44.000,00 \quad 108.800,00 \quad 16.800,00 \quad 52.000,00$ $\mathrm{R} \$ 308.800,00$

Custo no semestre

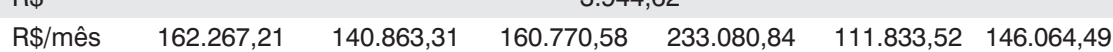

Fonte: Adaptado de Bordonalli (2007) 
Tabela 4 - Dados sobre o levantamento de custos do processo global (reciclagem de plásticos + tratamento de efluentes), Cenário ll: tratamento de efluentes na própria indústria e descarte na rede pública

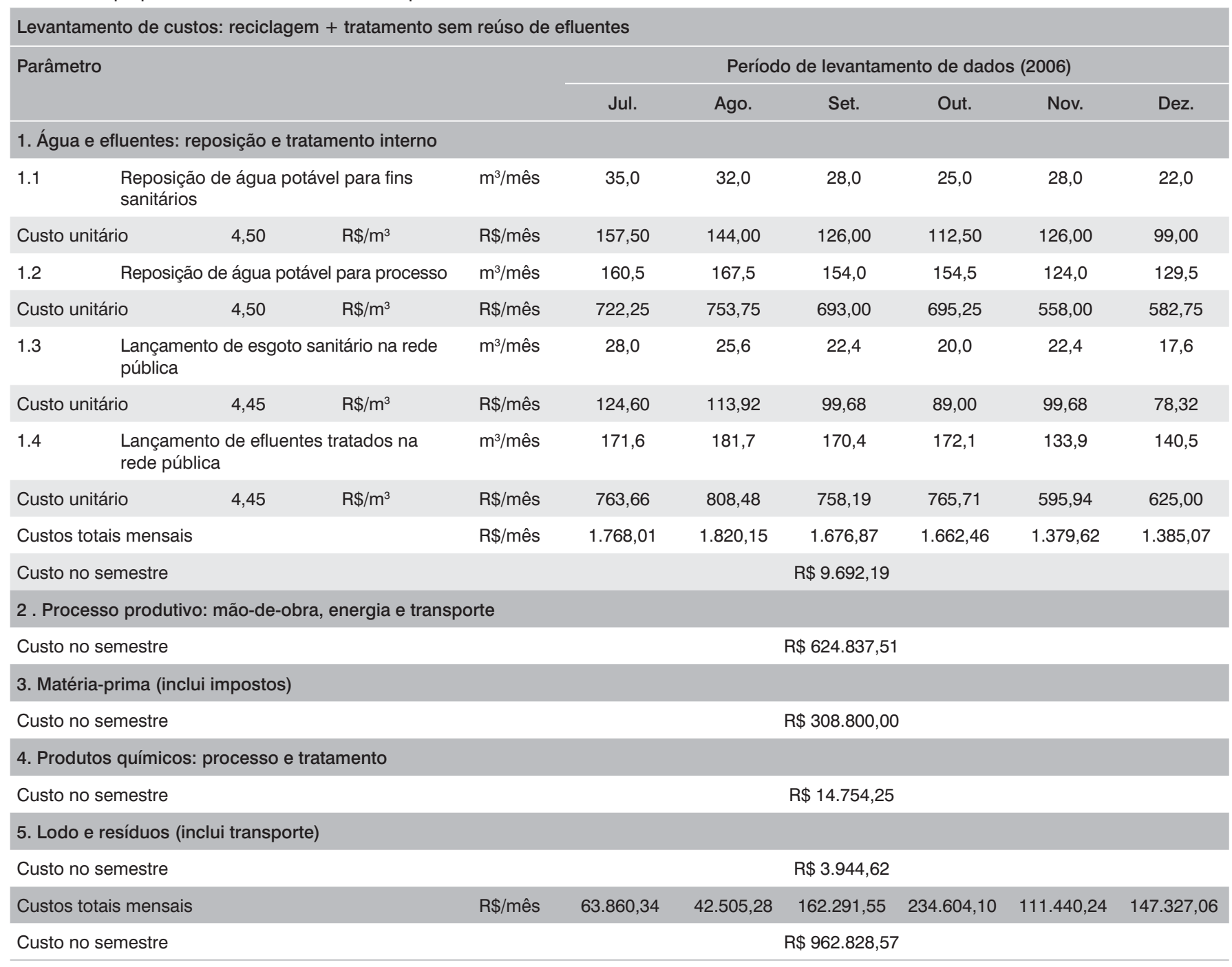

Fonte: Adaptado de Bordonalli (2007)

manifestados nas leituras de condutividade, o que impede o fechamento do circuito hídrico indefinidamente. Dessa forma, recomenda-se que haja uma renovação da água do sistema a cada semestre;

- o STAR proposto manifestou alto desempenho da redução de valores de turbidez, óleos e graxas, com eficiências superiores a 90\%. Para a DBO, DQO e surfactantes, as eficiências obtidas foram próximas a $60 \%$, impedindo o lançamento dos efluentes tratados na rede pública a cada semestre. Destaca-se que nessa situação a qualidade dos efluentes tratados adapta-se perfeitamente ao reúso, não interferindo na eficiência da lavagem dos plásticos, tampouco na qualidade dos pellets produzidos;

- o tratamento de efluentes gerados nessa atividade, implantandose o reúso, exige o emprego de hidroxicloreto de alumínio, soda cáustica, polieletrólito catiônico, em dosagens de, aproximadamente, 4,0 g/L; 6,0 g/L; 7,0 mg/L, respectivamente;
- são gerados dois tipos de resíduos nas atividades produtivas e no tratamento de efluentes. Os de Classe II, decorrentes do processo de lavagem que se constituem, basicamente, de fragmentos de plásticos de polímeros distintos de PE, além de resíduos de rótulos das embalagens recicladas. Os de Classe I surgem no processo de tratamento dos efluentes na forma de lodo que deve sofrer desaguamento antes de seu destino a aterro industrial. Suas produções unitárias foram de $6,1 \mathrm{~kg} / \mathrm{ton}$ e 167,6 kg/ton de material plástico reciclado $50,3 \mathrm{~kg}$ (matéria seca)/ton), respectivamente;

- o uso de big bags como unidades de recepção, desaguamento e acondicionamento de lodos gerados no tratamento de efluentes demonstrou grande praticidade operacional em comparação ao uso de leitos de secagem convencionais. Além disso, proporcionou excelente capacidade de retenção de sólidos e de drenagem da fase líquida, elevando a concentração para valores próximos 
Tabela 5 - Dados sobre o levantamento de custos do processo global (reciclagem de plásticos + tratamento de efluentes), Cenário III: tratamento de efluentes por terceiros

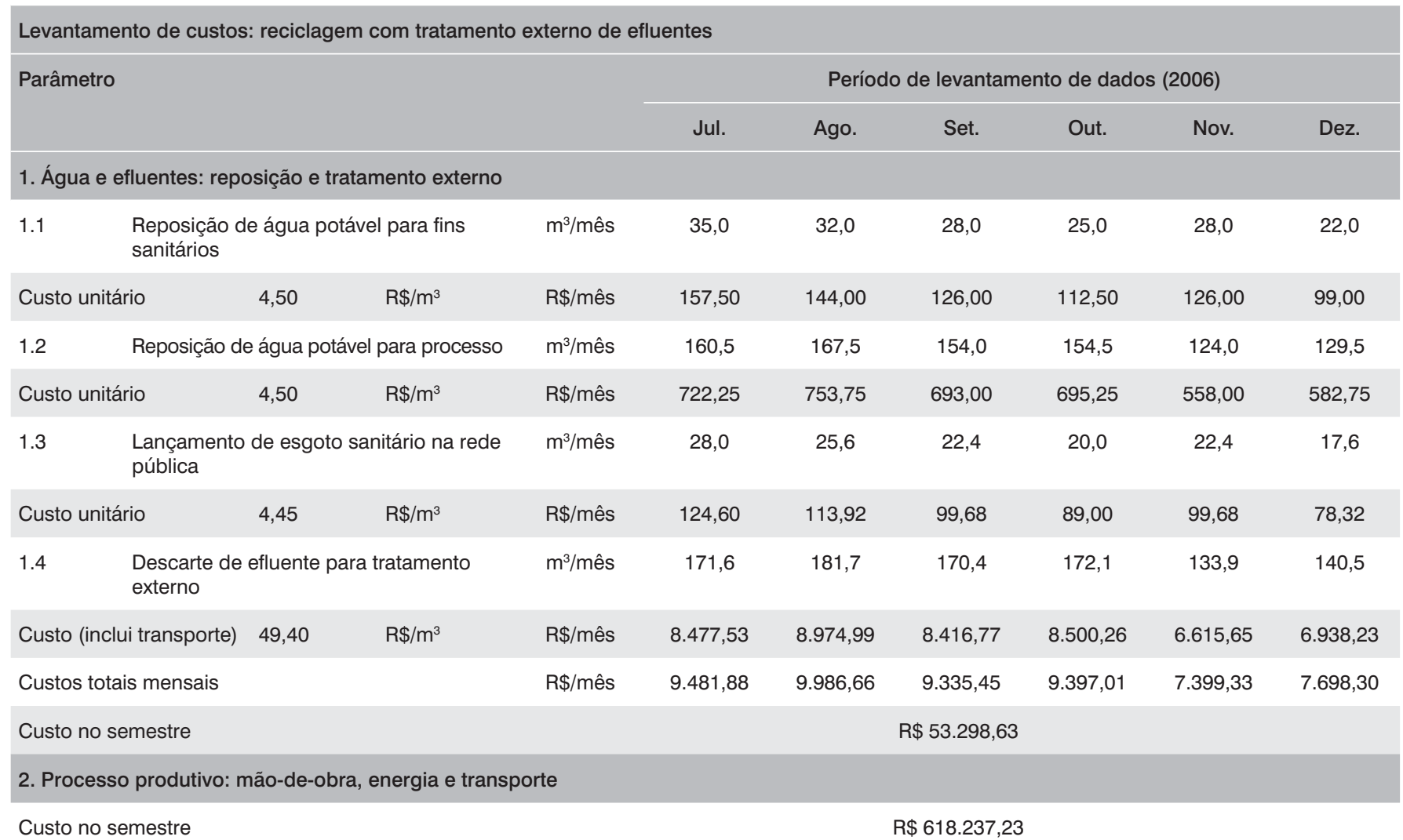

\section{Matéria-prima (inclui impostos)}

Custo no semestre

$\mathrm{R} \$ 308.800,00$

4. Produtos químicos: processo e tratamento

\begin{tabular}{|c|c|c|c|c|c|c|c|c|c|c|}
\hline 4.1 & \multicolumn{3}{|c|}{$\begin{array}{l}\text { Compra de tensoativo para lavagem de } \\
\text { plásticos }\end{array}$} & L/mês & 200 & 200 & 200 & 200 & 200 & 200 \\
\hline \multicolumn{2}{|c|}{ Custo médio unitário } & 4,45 & $\mathrm{R} \$ / \mathrm{kg}$ & $\mathrm{R} \$ / \mathrm{mês}$ & 890,00 & 890,00 & 890,00 & 890,00 & 890,00 & 890,00 \\
\hline \multicolumn{4}{|c|}{ Custos totais mensais } & $\mathrm{R} \$ / \mathrm{mês}$ & 890,00 & 890,00 & 890,00 & 890,00 & 890,00 & 890,00 \\
\hline \multicolumn{4}{|c|}{ Custo no semestre } & \multicolumn{7}{|c|}{$\mathrm{R} \$ 5.340,00$} \\
\hline 5.1 & \multicolumn{3}{|c|}{$\begin{array}{l}\text { Resíduos da banheira para aterro } \\
\text { sanitário (seco) }\end{array}$} & ton/mês & 0,30 & 0,40 & 0,45 & 0,50 & 0,25 & 0,30 \\
\hline Cus & lio unitário & 82,50 & $\mathrm{R} \$ /$ ton & $\mathrm{R} \$ / \mathrm{mês}$ & 24,75 & 33,00 & 37,13 & 41,25 & 20,63 & 24,75 \\
\hline \multicolumn{4}{|c|}{ Custos totais mensais } & $\mathrm{R} \$ / \mathrm{mês}$ & 24,75 & 33,00 & 37,13 & 41,25 & 20,63 & 24,75 \\
\hline \multicolumn{4}{|c|}{ Custos totais mensais } & $\mathrm{R} \$ / \mathrm{mês}$ & $168.744,78$ & $147.580,04$ & $166.543,72$ & $238.135,23$ & $114.332,28$ & $150.521,32$ \\
\hline \multicolumn{4}{|c|}{ Custo no semestre } & \multicolumn{7}{|c|}{$\mathrm{R} \$ 985.857,37$} \\
\hline
\end{tabular}

Fonte: Adaptado de Bordonalli (2007)

a 30\% após um período de secagem de 15 dias, em sequência ao seu preenchimento diário por cerca de 15 dias, a partir de descargas de lodo primário e químico, com concentrações médias de sólidos de 8 e $2,5 \%$, respectivamente.

\section{Agradecimentos}

Agradecemos às empresas Labormax e Prior Pak, pela possibilidade de desenvolvimento deste trabalho. 


\section{Referências}

BORDONALLI, A.C.O. Reúso de água em indústria de reciclagem de embalagens plásticas: aspectos econômicos e ambientais em modelo de escala real. 198 p. Tese (Doutorado em Saneamento e Ambiente) Faculdade de Engenharia Civil, Arquitetura e Urbanismo da Unicamp, Campinas, São Paulo, 2007.

BORDONALLI, A.C.O.; MENDES, C.G.N. Estudo de tratabilidade de águas de lavagem de plásticos contaminados com óleo lubrificante, visando reúso. In: SEMINÁRIO DE ACOMPANHAMENTO DE PESQUISA EM SANEAMENTO E AMBIENTE, 2. Anais... Campinas: Universidade Estadual de Campinas - Unicamp, p. 21-23, 2005.

GIORDANO, G. Avaliação ambiental de um balneário e estudo de alternativa para controle da poluição utilizando o processo eletrolítico para o tratamento de esgotos. 137 f. Dissertação (Mestrado em Ciência Ambiental) - Programa de Pós-Graduação da Universidade Federal Fluminense, Niterói, Rio de Janeiro, 1999
MIERZWA, J.C. O uso racional e o reúso como ferramentas para o gerenciamento de águas e efluentes na indústria: estudo de caso da KODAC Brasileira. Tese (Doutorado em Engenharia Civil) - Faculdade de Engenharia Civil da Universidade de São Paulo - USP, São Paulo, 2002.

MIERZWA, J.C.; HESPANHOL, I. Água na indústria: uso racional e reúso. São Paulo: Oficina de Textos, 2005.

SANTOS, S.G.; MIGUEL, E.N. Oportunidades para redução de efluentes líquidos industriais: caso da OPP Química S.A., 2002. Monografia (Especialização em Gerenciamento e Tecnologias Ambientais na Indústria) - Escola Politécnica da UFBA, Salvador, 2002.

WESTERHOFF, G.P; CHOWDHURY, Z.K. Water treatment systems. In: MAYS, W.L. Water resources handbook. New York: McGraw-Hill, p. 17.114.41, 1996. 